\title{
Febrile convulsions: intellectual progress in relation to anticonvulsant therapy and to recurrence of fits
}

\author{
J ALDRIDGE SMITH AND SHEILA J WALLACE \\ Department of Child Health, Welsh National School of Medicine, and University Hospital of Wales
}

SUMMARY One hundred and fifteen of 121 children consecutively admitted to hospital, each with his first febrile convulsion, were subsequently assessed on the Griffiths's mental development scales during a period of 24 months The effect of anticonvulsant medication on intellectual development was studied in 50 of the 73 children without recurrence of convulsions who had either continuous phenobarbitone, continuous sodium valproate, or no drugs during the 24 -month period. The effect of further fits was studied in 42 of the 115 children who had recurrences. Children with further febrile convulsions showed a decrease in Griffiths's development quotient between the initial and 24-month assessment, whereas children with no subsequent fits showed a trend in the reverse direction. The increase in Griffiths's development quotient in children with no subsequent fits was found irrespective of whether the children were on anticonvulsant medication, but there was a non-significant tendency for this increase to be greatest in the group without drugs. The present study suggests that further fits after an initial febrile convulsion are likely to be more detrimental in terms of overall intellectual development than continuous medication with either phenobarbitone or sodium valproate. If the decision to treat is based on the risk of further fits, the present study supports continuous anticonvulsant medication if this risk is significantly increased, until the child is pasE. the vulnerable period. In children at low risk of further febrile fits, intellectual development may be better if drugs are avoided.

When contemplating the use of anticonvulsants in the prophylaxis of febrile convulsions, it is important to consider the possible effects on the developing nervous system both of recurrent fits and anticonvulsant drugs.

Severe neurodevelopmental sequelae are reported in some series ${ }^{1-4}$ but others have stressed the apparently benign nature of recurrent febrile convulsions. ${ }^{5}$ In some circumstances repeated fits with fever presage later epilepsy. ${ }^{6-9}$ Phenobarbitone $^{10-13}$ and sodium valproate ${ }^{14-16}$ have both been shown to reduce the recurrence risk significantly. Unacceptable side effects are common with phenobarbitone ${ }^{17-19}$ and there is some suggestion that prolonged administration might have a deleterious effect on intellectual development. ${ }^{20}$ The possibility that sodium valproate has a slowing effect on mental development has been suggested. ${ }^{21}$ No report has considered the effects of repeated febrile convulsions and the use of anticonvulsants.

The present longitudinal investigation was designed to examine prospectively the intellectual development of any child admitted to hospital with a first febrile convulsion during the $\mathbf{2 4}$ months from the time of his initial fit. Throughout a 2-year period during which no further fit occurred, children who received continuous treatment with phenobarbitone or sodium valproate are compared with those who received no anticonvulsant. The effects of recurrent fits on development are examined.

\section{Patients and methods}

A consecutive series of 121 children admitted to the five paediatric units in Cardiff and Newport between April and December 1976, each with a first convulsion associated with a fever of at least $38^{\circ} \mathrm{C}$, was identified. The age range was 6 months to 5 years.

Between 2 and 3 weeks after the initial convulsion $\omega$ and before anticonvulsant therapy was considered, an initial detailed psychological assessment was performed. This included the use of the Griffiths's mental development scales. ${ }^{22} 23$ The children were then allocated by one of us (SJW) to a treatment 
regimen. The parents of those with at least one factor giving a significant risk of recurrence ${ }^{24}$ were advised alternately to give their children continuous phenobarbitone or sodium valproate. All other children were advised sequentially to take phenobarbitone, sodium valproate, or no drugs. Even among those considered at high risk of another convulsion, there were parents who were unwilling to give regular anticonvulsants. Thus the groups eventually receiving phenobarbitone, sodium valproate, or no treatment were comparable for factors considered to carry a risk of recurrence of seizures. The phenobarbitone dosage was $4-5 \mathrm{mg} / \mathrm{kg}$ per day, and that of sodium valproate $20-30 \mathrm{mg} / \mathrm{kg}$ per day. The clinical psychologist was not informed of the treatment group to which each child had been allocated and continued to work 'blind' throughout the study. Blood anticonvulsant levels were checked by the physician immediately after each psychological testing.

One hundred and fifteen of the total group were followed up with repeated comprehensive psychological assessments for 2 years. The 6 children from whom full details were not available did not differ significantly in any baseline respect from the 115 for whom the information was complete.

\section{Results}

The data have been analysed using an analysis of variance followed by between-group comparisons using the least squares difference (LSD) and Scheffe procedures.*

Anticonvulsant effects. During the 24 months after the first convulsion 73 of the 115 children had no subsequent fits. Of these, 50 had either the same drug or no drugs throughout the entire period. Thirteen received sodium valproate continuously (that is sodium valproate was present in the blood at each of the 5 times of testing-namely 2 to 3 weeks after starting treatment and at 6-monthly intervals up to 24 months after a fit), 16 received phenobarbitone continuously, and 21 had no drug. The other 23 of the 73 children had changes in their anticonvulsant regimens throughout the 24 months. If no subsequent fit occurred, no significant differences in Griffiths's development quotient (GDQ) were found either initially or 24 months later between the children who had been on sodium valproate continuously, those who had been on phenobarbitone continuously, and those who had

*A probability of $\mathrm{P}<0.05$ for the LSD procedure is equivalent to a $t$ test probability of $\mathrm{P}<0.05$ and a probability of $\mathrm{P}<0.05$ for the Scheffe procedure is equivalent to a $t$ test probability of 0.01 .25
Table 1 Griffiths's development quotients of 50 children with no subsequent fits and anticonvulsant status unchanged over 24 months

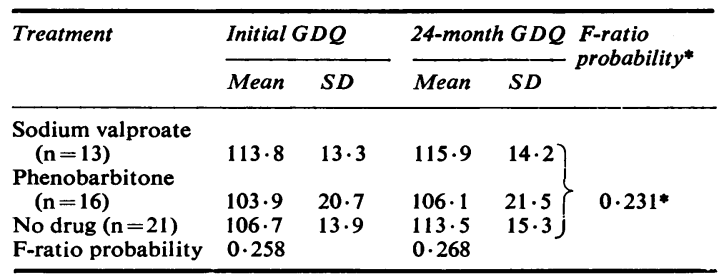

No group was significantly different from any other (LSD, Scheffe).

*Across all groups: initial and 24-month testings.

received no anticonvulsant. There was a nonsignificant rise in GDQ across all groups, but this was greatest in the no drug group (Table 1).

Further fits. When the 42 children who each had had at least one further fit were compared with the 73 who had not, there was no significant difference between the two groups on the initial assessment of GDQ. However, at 24 months, although children who had recurrences still had a mean GDQ within the average range, they had significantly lower GDQs than those who had had a single fit (Table 2). This difference was investigated further according to number of further fits. The $\mathbf{4 2}$ children with further fits were subdivided: 25 had one further fit, 10 had two further fits, and 7 had at least three further fits. These three groups are compared with the children who did not have a further fit (Table 3). The large standard deviation of the mean GDQ for the children with three or more further fits was owing to the presence of Case 55 who was very severely physically and mentally handicapped. Comparisons with this child excluded are therefore shown at the bottom of Table 3 .

On initial assessment of GDQ the group with no recurrences is significantly different from the group with three or more further fits (LSD $P<0.05$ ) but the latter group does not remain significantly different if Case 55 is excluded. None the less, their mean GDQ still holds the lowest rank position.

In terms of change in GDQ over 24 months the group with no further fits showed an increase,

Table 2 Griffiths's development quotients in 115 children with or without recurrence of fits

\begin{tabular}{|c|c|c|c|c|c|}
\hline \multirow[t]{2}{*}{ Subsequent fits } & \multirow{2}{*}{$\begin{array}{l}\text { Number } \\
\text { of children }\end{array}$} & \multicolumn{2}{|c|}{ Initial $G D Q$} & \multicolumn{2}{|c|}{ 24-month $G D Q$} \\
\hline & & Mean & $S D$ & Mean & $S D$ \\
\hline $\begin{array}{l}\text { Absent } \\
\text { Present }\end{array}$ & $\begin{array}{l}73 \\
42\end{array}$ & $\begin{array}{l}106 \cdot 5 \\
100 \cdot 9\end{array}$ & $\begin{array}{l}16 \cdot 9 \\
21 \cdot 1\end{array}$ & $\begin{array}{l}109 \cdot 2^{*} \\
96 \cdot 9^{*}\end{array}$ & $\begin{array}{l}18 \cdot 7 \\
20 \cdot 0\end{array}$ \\
\hline F-ratio probability & & & & .003 & \\
\hline
\end{tabular}

*Difference between groups significant (Scheffe $\mathrm{P}<0.05$ ). 
Table 3 Griffiths's development quotients in 115 children without recurrence of fits and with one, two, or at least three recurrences

\begin{tabular}{|c|c|c|c|c|c|}
\hline \multirow{2}{*}{$\begin{array}{l}\text { Number of } \\
\text { recurrences }\end{array}$} & \multirow{2}{*}{$\begin{array}{l}\text { Number } \\
\text { of children }\end{array}$} & \multicolumn{2}{|c|}{ Initial $G D Q$} & \multicolumn{2}{|c|}{ 24-month $G D Q$} \\
\hline & & Mean & $S D$ & Mean & $S D$ \\
\hline $\begin{array}{l}\text { None } \\
\text { One } \\
\text { Two } \\
\text { Three or more }\end{array}$ & $\begin{array}{r}73 \\
25 \\
10 \\
7\end{array}$ & $\begin{array}{c}106 \cdot 5 \ddagger \\
101 \cdot 9 \\
109 \cdot 1 \\
85 \cdot 6 \ddagger\end{array}$ & $\begin{array}{l}16 \cdot 9 \\
16 \cdot 5 \\
14 \cdot 1 \\
35 \cdot 9\end{array}$ & $\begin{array}{l}109 \cdot 2 \\
100 \cdot 1 \dagger \\
100 \cdot 2 \\
81 \cdot 0^{*} \dagger\end{array}$ & $\begin{array}{l}18 \cdot 7 \\
15 \cdot 4 \\
14 \cdot 1 \\
33 \cdot 6\end{array}$ \\
\hline $\begin{array}{l}\text { Three or more } \\
\text { (excluding Case 55) } \\
\text { F-ratio probability }\end{array}$ & 6 & $98 \cdot 0$ & $15 \cdot 6$ & $00^{93 \cdot 2 \dagger}$ & $10 \cdot 6$ \\
\hline
\end{tabular}

$\ddagger$ Difference between groups significant (LSD P $<0.05$ ).

Compared with 24 months after no recurrence, difference significant ${ }^{*}$ Scheffe $P<0.05, \dagger$ LSD $P<0.05$.

whereas all the groups with further fits showed a decrease in score.

At 24 months the differences between the group with no recurrences and the groups with at least three recurrences are significant (entire group, Scheffe $\mathbf{P}<0.05$; excluding Case 55, LSD $P<0.05$ ). The GDQ difference between the no recurrence group and the one further recurrence group is also significant (LSD $P<0.05$ ). The mean group GDQs show that at 24 months the group with no further fits had the highest mean GDQ $(109 \cdot 2)$, the groups with one and two further fits intermediate scores (mean GDQ 100.1 and 100.2 respectively), and the groups with three or more further fits the lowest mean GDQs (81.0 (entire group) and 93.2 (excluding Case 55) ).

\section{Discussion}

The clearest finding from this clinical study is that those children with subsequent fits show a decrease in GDQ between initial and 24-month assessment, whereas children with no subsequent fits-whether or not on anticonvulsant medication-show a trend in the reverse direction.

The effect of anticonvulsant medication itself in children with no subsequent fits is less clear. On the one hand, there is no significant GDQ difference across drug and no drug groups, on the other, the no drug group shows the greatest rise in GDQ during the 24 months. Few other studies have reported on the intellectual effects of the prolonged use of phenobarbitone and sodium valproate. Camfield et al.$^{20}$ cautiously suggested that prolonged administration of phenobarbitone might have adverse effects on cognitive abilities. Trimble ${ }^{21}$ from a retrospective study in children with severe seizure disorders on multiple drug regimens, suggested that sodium valproate might have a slowing effect on mental development. The present study lends tentative support to the suggestion of these two studies that prolonged continuous medication with phenobarbitone and sodium valproate may lead to slightly less than optimal intellectual development.

With regard to the effects of recurrent fits, results of previous studies are conflicting. Ellenberg and Nelson ${ }^{5}$ described recurrent seizures as unharmful. However, in their study the children were chosen on the basis of normality of their siblings and availability at age 7 years, and the comparison of intelligence levels before and after recurrent attacks was complicated by the use of different scales at initial and final testing. Schiottz-Christensen and Bruhn, ${ }^{26}$ in their study on twin pairs discordant for febrile convulsions, give evidence in support of the adverse effect of the convulsions themselves. In the present study some of the numbers are small and the results not conclusive, but at 24 months, in addition to the significant difference between the no further fit group and the three or more recurrence group, the trend for the no recurrence group to have the highest GDQ, the one and two recurrences groups to have intermediate scores, and the three or more recurrences group to have the lowest GDQ score, suggests that further fits may, indeed, be adversely affecting development. Although the possibility is not excluded that factors which might predispose to another seizure ${ }^{27}$ might also predispose to lower levels of intellectual development, the finding that GDQ falls with recurrence(s) and increases with no subsequent fit implicates the seizures themselves as adverse factors for intellectual development.

In conclusion, the present study suggests that subsequent fits after an initial febrile convulsion are likely to be more detrimental in terms of overall intellectual development than continuous, prolonged ( 2 years) medication with either phenobarbitone or sodium valproate. Provided there are no further fits there is some indication that anticonvulsant medication may lead to slightly less than optimal intellectual development. In terms of treatment, different approaches for children at high and low risk are indicated. For children at high risk the present study supports continuous anticonvulsant medication until the child is past the vulnerable age. For those at low risk the present evidence suggests that treatment without the use of anticonvulsant drugs should be considered.

We thank the paediatricians in Cardiff and Newport who allowed us to study their patients, and Mrs D Dupres for secretarial assistance.

Reckitt-Labaz and the Medical Research Fund of the University Hospital of Wales provided financial support. 


\section{References}

1 Aicardi J, Chevrie J J. Febrile convulsions: neurological sequelae and mental retardation. In: Brazier M A B, Coceani $\mathrm{F}$, eds. Brain dysfunction in infantile febrile convulsions. New York: Raven Press, 1976: 247-57.

2 Falconer M A, Serafetinides E A, Corsellis J A N. Etiology and pathogenesis of temporal lobe epilepsy. Arch Neurol 1964; 10: 233-48.

3 Lennox-Buchthal M A. Febrile convulsions: a reappraisal. Amsterdam: Elsevier, 1973.

4 Ounsted C, Lindsay J, Norman R. Biological factors in temporal lobe epilepsy. London: Heinemann, 1966.

5 Ellenberg J H, Nelson K B. Febrile seizures and later intellectual performance. Arch Neurol 1978; 35: 17-21.

- Frantzen E, Lennox-Buchthal M, Nygaard A, Stene J. A genetic study of febrile convulsions. Neurology 1979; 20: 909-17.

7 Millichap J G. Febrile convulsions. New York: Macmillan, 1968.

8 Nelson K B, Ellenberg $\mathbf{J} \mathbf{H}$. Predictors of epilepsy in children who have experienced febrile seizures. $N$ Engl $J$ Med 1976; 295: 1029-33.

- Wallace S J. Spontaneous fits after convulsions with fever. Arch Dis Child 1977; 52: 192-6.

10 Faerø O, Kastrup K W, Lykkegard Nielsen E L, Melchior J C, Thorn I. Successful prophylaxis of febrile convulsions with phenobarbital. Epilepsia 1972; 13: 279-85.

11 Thorn I. A controlled study of prophylactic long-term treatment of febrile convulsions with phenobarbital. Acta Neurol Scand [Suppl] 1975; 60: Supplement, 67-73.

12 Wallace S J. Continuous prophylactic anticonvulsants in selected children with febrile convulsions. Acta Neurol Scand [Suppl] 1975; 60: Supplement, 62-6.

13 Wolf S M, Carr A, Davis D C, et al. The value of phenobarbital in the child who has had a single febrile seizure: a controlled prospective study. Pediatrics 1977 ; 59: 378-85.

14 Cavazzuti G B. Prevention of febrile convulsions with dipropylacetate (Depakine (B). Epilepsia 1975; 16: 647-8.

15 Ngwane E, Bower B D. Continuous sodium valproate or phenobarbitone in the prevention of 'simple' febrile convulsions. Comparison by a double-blind trial. Arch Dis Child 1980; 55: 171-4.

16 Wallace S J, Aldridge Smith J A. Successful prophylaxis against febrile convulsions with valproic acid or phenobarbitone. Br MedJ 1980; 280: 353-4; 612 .

17 Ounsted C. The hyperkinetic syndrome in epileptic children. Lancet 1955; ii : 303-11.

18 Hammill J H, Carter S. Febrile convulsions. N Engl J Med $1966 ; 274$ : 563-5.

19 Wolf S M, Forsythe A. Behavior disturbance, phenobarbital, and febrile seizures. Pediatrics 1978; 61 : 728-31.

20 Camfield C S, Chaplin S, Doyle A-B, et al. Side effects of phenobarbital in toddlers; behavioural and cognitive aspects. J Pediatr 1979; 95: 361-5.

21 Trimble M. The effects of anticonvulsants in epileptic children. Presented to British Paediatric Neurology Association, Liverpool, 1978.

22 Griffiths R. The abilities of babies. London: University of London Press, 1954.

${ }^{23}$ Griffiths R. The abilities of young children. London: Child Development Research Centre, 1970.

24 Wallace S J. Recurrence of febrile convulsions. Arch Dis Child 1974; 49: 763-5.

25 Nie N H, Hadlai Hull C, Jenkin J G, Steinbrenner K, Bent D H. Statistical package for the social sciences. New York: McGraw Hill, 1975: 398-433.

${ }^{26}$ Schiottz-Christensen E, Bruhn P. Intelligence, behaviour, and scholastic achievement subsequent to febrile convulsions: and analysis of discordant twin-pairs. Dev Med Child Neurol 1975; 15: 565-75.

27 Wallace S J, Aldridge Smith J. Recurrence of convulsions in febrile children on no anticonvulsant. In: Penry $\mathbf{J} \mathbf{K}$, Dam M, eds. Advances in epileptology: the XII Epilepsy International Symposium, Copenhagen 1980. New York: Raven Press, 1981.

Correspondence to Mrs J Aldridge Smith, Departof Psychiatry, University of Leeds, 15 Hyde Terrace, Leeds LS2 9LT.

Received 16 March 1981 